\title{
INVESTIGATING THE IMPORTANCE OF SELF-ACCEPTANCE AND SELF-EFFICACY ON WEIGHT MANAGEMENT IN A DEVELOPING COUNTRY
}

\begin{abstract}
The growing rates of obesity in both developed and developing countries are alarming. Most studies on obesity mainly focus on individuals in developed countries with ready access to food. Limited studies explore obesity in developing countries with limited access to healthier foods. In addition, studies show self-acceptance and self-efficacy is essential to healthier well-being. The purpose of this study is (a) to explore the impact of self-acceptance on individuals' self-efficacy to weight management and (b) to investigate the impact of selfefficacy on individuals' attitude and intention in regards to weight managements. Using data from Indonesia $(\mathrm{N}=499)$, the respondents are divided based on their Body Mass Index (BMI). The results show self-acceptance significantly influenced individuals' self-efficacy, especially for individuals who are obese. Furthermore, self-efficacy did not influence individual attitude toward weight management. Finally, attitude toward weight management only influenced people who are obese and not individuals who are overweight. The results of this study will have significant implications to government, social marketers, and not-forprofit organisations in fighting the epidemic in developing countries.
\end{abstract}

Keywords: obesity, self-efficacy, self-acceptance, weight management

The prevalence of obesity has been increasing significantly in both developed and developing nations (Bhusory \& Jeewon, 2014; Grammatikopoulou et al., 2008; Li et al., 2010; Mcleay\& Oglethorpe 2013; Usfar, 2010). In 2014, more than 1.9 billion adults 18 years old and over are overweight; 600 million are obese (WHO 2015). Obesity is responsible for about $5 \%$ of all deaths a year globally with an estimated cost of $\$ 2$ trillion annually (McKinsey, 2014). In addition, people's diets have been significantly changed with significantly more fat, meat, sugars, and bigger portion sizes (Bhurosy \& Jeewon, 2014; Previte \& Gurrieri 2015; Kempt \& Grier 2013)

Between 1980 and 2008, the number of people affected in developing countries rose from 250 million to 904 million (Overseas Development Institute, 2014). Studies on obesity prior to 1989 suggest obesity in the developing countries is essentially a disease of the socioeconomic elite (Carlos et al., 2004; Michaelidou et al., 2012; Sobal \& Stunkard, 1989; 
Stunkard et al., 2000). Nonetheless, recent studies show that obesity in the developing world can no longer be considered a disease of people with higher socio economic status (SES) (Carlos et al., 2004). For example, in Brazil, obesity is increasing faster among people with lower SES (Gupta et al., 2012; Monteiro et al., 1995; Monteiro et al., 2004). Improved access to food and decreased physical activity level has been considered the main cause of overweight and chronic metabolic diseases in developing countries (Hoffman, 2004; Bhurosy \& Jeewon, 2014).

To make matters worse, in the last few years, childhood obesity is now much higher in developing countries than in developed countries (World Health Organization, 2009). Nonetheless, the number of studies conducted in the developing countries is minimal. Studies show strengthening an individual's self-acceptance beliefs is essential to the psychological well-being of that individual (McInnes, 2006; Ellis ,1995). Unconditional self-acceptance means individuals are able to accept themselves unconditionally whether other people approve of them or they behave correctly (McInnes, 2006; Elly, 1977). People's inability to unconditionally accept themselves sometimes extends to their inability to accept other people (Flett et al., 2003). Thus, the purpose of this study is: (a) to explore the impact of selfacceptance on individuals' self-efficacy to weight management and (b) to investigate the impact of self-efficacy on individuals' attitudes and intentions regarding to weight management. This study will make several contributions: (1) investigating the influence of self-acceptance as a precursor to self-efficacy and subsequently, testing the impact of selfefficacy to weight management; (2) this is one of the few studies, exploring wight management in a developing country (i.e. Indonesia). The results of this study will have significant implications for governments, social marketers, and not-for-profit organisations in fighting the weight epidemic in developing countries. 


\section{LITERATURE REVIEW AND HYPOTHESIS DEVELOPMENT}

Based of self-efficacy theory (Bandura, 1977), the study proposes that self-acceptance will influence individuals' self-efficacy. Subsequently, self-efficacy will influence individuals' attitude and intentions. Figure 1 summarized the conceptual framework of this study. The next section will discuss the hypotheses development of this study.

\section{Insert Figure 1 About Here}

\section{Self-Acceptance}

Derived from self-concept, self-acceptance can be defined as to what extent the self-concept is congruent with the individual's description of the individual's 'ideal self' (Crowne and Stephends, 1961). Rubin (1967, p. 234) describes self-acceptance as 'a willingness to confront ego-alien as well as ego-syntonic aspects of the self and to accept rather than deny their existence'. One key aspect of self-acceptance is the ability and willingness to let others see one's true self (Carson \& Langer, 2006). It results in an individual feeling about him or herself as one who has 'unique worth' (Rogers, 1951; Shepard, 1979). The self-rejecting individuals often consider themselves of little worth and are likely to have other symptom of maladjustment (Shepard, 1979). Self-acceptance is critical to mental health (Carson and Langer, 2006). Subsequently, lower levels of unconditional self-acceptance correlate with higher levels of depression, anxiety (Carson \& Langer, 2006; Chamberlain \& Haaga, 2001; Flett et al., 2003; Shepard, 1979), and parental workaholism (Chamberlin and Zhang, 2009). Greenspon (2000) suggested that feelings of conditional self-acceptance are central to both the cause and tendency of perfectionism. It is feasible to suggest that self-acceptance will influence people's self-efficacy in regards to weight management. Hence, this study hypothesizes:

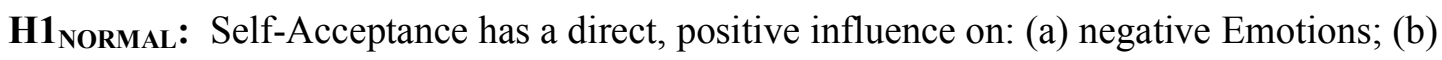
available; (c) social; (d) physical and (e) positive Self-Efficacy. 
H1 OVERWEIGHT: Self-Acceptance has a direct, positive influence on: (a) negative emotions; (b) available; (c) social; (d) physical and (e) positive self-efficacy.

H1 $1_{\text {OBESE: }}$ : Self-Acceptance has a direct, positive influence on: (a) negative emotions; (b) available; (c) social; (d) physical and (e) positive Self-Efficacy.

Moreover, a significant relationship exists between self-acceptance and self-esteem. Meisenhelder (1985) suggested self-esteem is essential to maintaining mental and physical health. Individuals with high self-acceptance are more confident in their ability to accomplish their efforts. Consequently, they are more likely to have positive attitudes toward weight loss. Flett et al. (2003) found higher levels of unconditional self-acceptance correlated with lower levels of depression. Hence, the study suggests:



H2 OVERWEIGHT: Self-Acceptance has a direct, positive influence on attitudes.

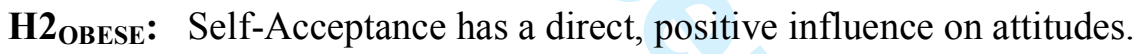

\section{Self-Efficacy}

Self-efficacy theory is an integrative cognitive-social learning framework empirically tested in a variety of treatment contexts (Bandura, 1977). The theory suggests all processes of psychological change operate through the adaptation of the individual's expectancies of personal mastery or efficacy (Bandura, 1982). Self-efficacy can be defined as an individual's judgement of her or his ability to cope effectively in a situation (Bandura, 1977; Clark et al., 1991). It does not reflect an individual's skills; instead, it reflects to an individual's judgement of what he or she can do with the skills they possesses (de Vries et al., 1988). Self-efficacy is different from perceived behavioral control. Self-efficacy is related to factors internal to the individual while perceived behavioral control is related to external factors (e.g. cooperation of other people, availability of time and money) (Ajzen \& Timko, 1986). Individuals' persistence and efforts to adopt specific behaviour are closely correlated 
to the individuals' level of perceived self-efficacy (Bandura, 1977; Lee et a al., 2011).

Studies show that individuals with low efficacy expectations are unlikely to resist temptation to use the substance (Abrams \& Niaura, 1987), less likely to perform physical activity (Pan et al., 2009; Lee et al., 2011; Strachan et al., 2005; Sweet et al., 2012), more likely to suffer from postnatal depressive symptomatology (Leahy-Warren, 2009), experience phobias (Bandura et al., 1980), smoke (Stuart et al., 1994), and engage in problem drinking (Burling et al 1989). In the context of weight loss, there are inconclusive results. Few studies found that self-efficacy is predictor of success of weight loss (Bernie \& Avard, 1986; Bradley et al., 1980; Brownell and Cohen, 1995). In contrast, other studies found self-efficacy is not a significant predictor of weight loss (e.g., Chao et al., 2000; Dennis \& Goldberg, 1996; Fontaine \& Cheskin, 1997). Considerable support exists for the role of self-efficacy as a determinant of intention (Fishbein \& Yzer, 2003; Sheeran et al., 1999; Sheppard et al., 1998). Theoretically, self-efficacy will have a direct effect on an individuals' attitude toward weight management. Thus, the study proposes:

H3 $_{\text {NORMAL }}$ : (a) negative Emotions; (b) available; (c) social; (d) physical and (e) positive selfefficacy has a direct positive influence on attitude.

H3 OverweIGHT: (a) negative emotions; (b) available; (c) social; (d) physical and (e) positive Self-Efficacy has direct positive influence on attitude.

H3 $3_{\text {OBESE }}$ : (a) negative Emotions; (b) available; (c) social; (d) physical and (e) positive selfefficacy has direct positive influence on attitude.

\begin{abstract}
Attitude
The attitude toward behaviour, either positive or negative, is a function of the beliefs concerning the perceived consequences of performing a specific action and a personal evaluation of each of those consequences (Deshpande et al. 2009; Godin, 1993). An individual who holds strong beliefs that positively valued outcomes will result from performing the behaviour (e.g., physical exercise) will have a positive attitude toward the
\end{abstract}


behaviour. On the contrary, an individual who holds strong belief that negatively valued outcomes will result from the behaviour will have a negative attitude (Ajzen \& Fisbhein, 1980; Montano \& Kasprzyk, 2008).

Studies have validated that attitude influences individuals' intentions toward various health-related behaviour in general (Conner \& Godin, 2007; Godin \& Kok, 1996) and in specific behaviour such as eating a low fat diet (Armitage \& Conner, 1999), exercise (Blue, 1995; Hausenblas et al. 1997; Hagger et al. 2002), leisure participation (Ajzen and Driver, 1991), family planning (Fishbein et al., 1980), smoking (Davey et al., 2013), using condoms (Chan and Fishbein, 1993; Trafimow, 2000), mammography utilization (Montono et al. 1997), sustainable consumption (De Pelsmacker et al., 2003; Tanner and Kast, 2003; Vermeir and Verbeke, 2006), and weight loss (Sejwacs et al., 1980; Schifter \& Icek, 1985). Studies show that attitude displays satisfactory reliability and validity toward intentions (Chatzisarantis et al., 2005; Ajzen \& Fishbein, 1980; Theodoraki, 1994). Despite their weight, individuals' attitudes toward weight lost will significantly influence their intention to exercise, lose weight, and eat healthy. Hence, the study proposes:

H4 $4_{\text {NORMAL }}$ : Attitude to lose weight has a direct, positive influence on (a) intention to exercise, (b) intention to lose weight, and (c) intention to eat healthy.

H4 Overweight: Attitude to lose weight has a direct, positive influence on (a) intention to exercise, (b) intention to lose weight, and (c) intention to eat healthy.

H4 OBESE: Attitude to lose weight has a direct, positive influence on (a) intention to exercise, (b) intention to lose weight, and (c) intention to eat healthy.

\section{METHODOLOGY}

\section{Sample}

The research context for this study is Indonesia. Indonesia is the fourth most populous nation with 255 million people (CIA, 2015). Indonesian gross domestic product per capita is around US\$ 10,700 (CIA, 2015). A recent report reveals Indonesia has just become the tenth most 
obese country with the number of overweight and obese adults doubling in the last decade (Ng et al., 2014; UNICEF, 2014). While successfully reducing malnutrition, Indonesia is now facing the problem of obesity (Faizal, 2012). Obesity often coexists with undernutrition with the percentage of obese people aged 18 and over at $21.7 \%$. What is more, $14 \%$ of Indonesia's children are overweight, increase from 11\% in 2007 (Usfar et al., 2010).

The researcher collected data for this study from a large university in three different cities in Indonesia: Surabaya, Yogyakarta, and Solo. Several research assistants distributed the survey to the students and staff in those universities. In addition, the researcher also distributed the survey to the staff in a large private hospital in Surabaya, Indonesia. A total of 575 surveys were distributed. Incomplete surveys with too many missing values were removed from the sample. Overall, 499 samples were usable. Respondents had to fill in their height and weight to calculate their BMI. Subsequently, the sample was divided to three BMI levels. Normal weight with a BMI of 18.5-24.9, overweight with a BMI of 25-29.9, and obese with a BMI of 30 or greater. In this study, 55\% were normal weight, $27 \%$ were overweight and $18 \%$ were obese. In the sample, $29 \%$ are male, $67 \%$ are female, and $4 \%$ were undeclared. Regarding age, $50 \%$ of the respondents were between $18-24$ years, $28 \%$ were between $25-34,14 \%$ were between $35-44 \%$ and $8 \%$ were above 45 years old. Moreover, $52 \%$ of the respondents had an income lower than 20 million rupiah, around US\$1467 (1USD $=13632$ Rupiah, as of 18 May 2016) and only 7\% had an income above 81 million rupiah, around US\$5941). Finally, 40.9\% of the respondents had high school degree, followed by Undergraduate (29.3\%) and Diploma (14.8\%). (Table 1 summarized the demographic profile of the respondents.

Insert Table 1 About Here

\section{Measurement items}


Self-acceptance was measured using Ryff's (1995) psychological well-being scales (e.g. in general, I feel confident and positive about myself). Self-efficacy was measured using ‘Weight Efficacy Life-Style Questionnaires’ from Clark et al. (1991). The self-efficacy scale consists of five constructs: (a) negative emotions (e.g. I can resist eating when I am anxious (nervous)); (b) availability (e.g. I can control my eating on the weekends); (c) social pressure (e.g. I can resist eating when I have to say "no' to others); (d) physical discomfort (e.g. I can resist eating when Ifee physically run down); and (e) positive activities (e.g. I can resist eating when I am watching TV). The constructs were measured using Likert scales with $1=$ strongly agree; 7 = strongly disagree.

Attitude toward losing weight and intention to lose weight, intention to exercise, and intention to eat healthy were measured using Ajzen's (1991) scales. Attitude (e.g. for me to lose weight in the next six month is; $1=$ good; $7=b a d$ ) and intention to lose weight (e.g. $I$ intend to lose weight in the next six months; $1=$ strongly agree; 7 =strongly disagree); intention to exercise (e.g. I intend to exercise in the next 7 days; $1=$ extremely likely; $7=$ extremely unlikely), and intention to eat healthy (e.g. I intend to eat more healthfully in the next 7 days; $1=$ extremely likely; $7=$ extremely unlikely).

\section{Data Analysis}

Using Structural Equation Modelling, the analysis followed Andersen and Gerbing's (1988) two-stage procedure. First, the goodness of the measurement instruments was analysed by Confirmatory Factor Analysis (CFA). Second, the structural relations among the theoretically proposed latent variables were analysed through SEM. Both the measurement model and the causal relations model were estimated for the model fit using the Maximum Likelihood Methods (Satorra and Bentler, 1994). The goodness-of-fit indicator for the measurement 
instrument $(\mathrm{NFI}=0.850 ; \mathrm{TLI}=0.926 ; \mathrm{CFI}=0.936 ; \mathrm{IFI}=0.937 ; \mathrm{RMSEA}=0.036$, easily exceeds the commonly accepted critical values (Andersen and Gerbing, 1988).

Table 2 shows the measurement instrument reliability can be confirmed as Cronbach's alpha exceeds the critical value of 0.8 (Cronbach, 1951) and Composite Reliability and Average Variance Extracted indexes also exceed the critical value of 0.7 and 0.5 respectively, except for positive activities (Fornell \& Larckler, 1981). In addition to the goodness-fit indicators, the researcher used two criteria to verify convergent validity. The results show the observed variables were significant and the average loads were above 0.7 (Hair et al., 2005).

\title{
Insert Table 2 About Here
}

Finally, the researcher checked the measurement model to ensure discriminant validity, First, inter-factor correlation was significant below 1. Second, for each pair of factors, the researcher verified the difference of ${ }_{X}^{2}$ between the proposed measurement model and a restricted model where the correlation between said factors was set at 1 (Fornell \& Larcker, 1981) was significant. The researcher conducted the variance extracted test and found that AVE for each factor was higher than the square of the correlation coefficient with each of the other factors (see Table 3). Thus, the test confirms the measurement model discriminant validity (Fornell and Larcker, 1981)

\author{
Insert Table 3 About Here
}

\section{RESULTS}

\section{Normal weight}

The results show self-acceptance significantly influenced negative self-efficacy $(\beta=0.277, \mathrm{p}$ $<0.01)$, available self-efficacy $(\beta=0.149, \mathrm{p}<0.01)$ and social self-efficacy $(\beta=0.310, \mathrm{p}<$ 0.01). Thus, H1a-NORMAL, H1b-NORMAL and H1c-NORMAL are supported. Nonetheless, self- 
acceptance did not influence physical self-efficacy and positive self-efficacy. Hence, H1dNORMAL and H1e-NORMAL are not supported. Moreover, the results support H2 $2_{\text {NORMAL, self- }}$ acceptance significantly influence people's attitude toward weigh loss $(\beta=0.148, \mathrm{p}<0.05)$.

Furthermore, self-efficacy significantly influenced positive self-efficacy. Thus, H3eNORMAL is supported. However, negative self-efficacy, available self-efficacy, social selfefficacy, and physical self-efficacy did not influence attitude toward losing weight. Therefore, H3a-NORMAL H3b-NORMAL, H3c-NORMAL and H3d $\mathrm{d}_{\text {NORMAL }}$ are not supported. Finally, attitude toward losing weight significantly influenced individuals' intention to lose weight ( $\beta$ $=0.845, \mathrm{p}<0.01)$ but not intention to exercise and eat healthy. Thus, H4a-NORMAL is supported but not H4b - NORMAL and H4c - NORMAL. Positive value means that individuals who have a negative attitude toward losing weight are more likely to have less intention to lose weight in the next six months.

\section{Overweight}

For individuals who are overweight, self-acceptance significantly influenced negative selfefficacy $(\beta=0.215, \mathrm{p}<0.05)$ and available self-efficacy $(\beta=0.214, \mathrm{p}<0.05)$. Hence H1aOVERWEIGHT and H1b-ovERWEIGHT are supported. However, self-acceptance did not significantly influence social self-efficacy, physical self-efficacy, and positive self-efficacy. Therefore, H1c-overweight, H1d-overweight, and H1e-overweight are not supported. Moreover, self-acceptance did not support people's attitude toward weight loss. Thus, $\mathrm{H} 2$ OVERWEIGHT is not supported.

All self-efficacies did not significantly influence attitude toward losing weight. Hence, H3a-overweight, H3b-overweight, H3c-overweIGHt, H3d-overweight and H3eOVERWEIGHT are not supported. Finally, attitude toward losing weight significantly influenced intention to lose weight $(\beta=0.866, \mathrm{p}<0.01)$ but not intention to exercise and eat healthy. 
Therefore, H4a-overweIGHT is supported while H4b-overweIGHT and H4c-overweIGHT are not supported.

\section{Obese}

The results for this group show that, except for physical self-efficacy, self-acceptance significantly influenced negative self-efficacy $(\beta=0.523, \mathrm{p}<0.01)$, available self-efficacy $(\beta$ $=0.400, \mathrm{p}<0.01)$, social self-efficacy $(\beta=0.421, \mathrm{p}<0.01)$, and positive self-efficacy $(\beta=$ 0.407, $\mathrm{p}<0.01$ ). Thus, H1a-obeSE, H1b-obeSe, H1c-obeSe, and H1e-obeSE are supported while H1d-oBESE is not supported. Moreover, for individuals who are obese, self-acceptance significantly influenced people's attitude toward weight loss $(\beta=0.366, \mathrm{p}<0.01)$.

Furthermore, the finding supports H3a-obeSE and H3d-obese. Negative self-efficacy $(\beta=-0.342, \mathrm{p}<0.01)$ negatively influenced individuals' attitudes toward losing weight. It shows individuals with high emotion self-efficacy are more likely to perceive weight loss negatively. In contrast, physical self-efficacy positively influenced an individual's attitude toward weight loss $(\beta=0.313, \mathrm{p}<0.01)$. It shows that individuals with high physical selfefficacy are more likely to have positive attitude toward weight loss. However, available selfefficacy, social self-efficacy, physical self-efficacy, and positive self-efficacy did not influence individuals' attitudes toward weight loss. Hence, H3b-oBese, H3c-obese, H3d-obese, and H3e-OBESE are not supported. Finally, individuals' attitudes toward losing weight significantly influenced their intention to lose weight $(\beta=0.779, \mathrm{p}<0.01)$, intention to exercise $(\beta=0.218, \mathrm{p}<0.05)$, and intention to eat healthy $(\beta=0.238, \mathrm{p}<0.05)$. Therefore, H4a-oBeSE, H4b-oBESE and H4c-oBESE are supported. Obese individuals who have negative attitude toward losing weight are more likely to have less intention to lose weight, exercise, and eat healthy in the future. Table 4 summarizes the structure equation model results for all weight categories. 


\section{Insert Table 4 About Here}

\section{DISCUSSION AND IMPLICATIONS}

The results show self-acceptance significantly influences individuals' self-efficacy, especially for individuals who suffer obesity. Individuals with low self-acceptance are more likely to have low self-efficacy and are thus unlikely to resist temptation. People with low selfacceptance will suffer from excessive focus on evaluation, which includes social comparisons with other people (Ellis, 1995).

Self-acceptance in this study does not focus on physical acceptance but focuses on having a positive self-image and being more confident about one's self. In the context of Indonesia, this study shows low self-acceptance resulted in low self-efficacy. The study supports other research that suggests obese women tend to eat more in response to emotional arousal and tend to have more of a negative self-image than their non-obese counterparts (Hooker \& Conviser, 1983; Dennis \& Goldberd, 1996). Therefore, social marketers need to train individuals to first accept themselves in spite of their deficiencies. Individuals need to understand their strengths and weaknesses and learn to accept themselves. The positive selfimage will eventually improve their self-efficacies. Confidence is needed to support people's ability to accomplish the behaviors required to lose weight.

Moreover, not all self-efficacy significantly influences people's attitude toward losing weight. For people who suffer from obesity, negative emotions self-efficacy has a negative impact of their attitude. Obese individuals with low self-efficacy on emotions tend to perceive losing weight as unpleasant and painful. Moreover, obese individuals with high physical self-efficacy are more likely to see the positive aspects of weight loss.

In general, the results of this study show that specific self-efficacies affected individuals differently and not all self-efficacies correlated well with weight loss (Edell et al., 1987). Social marketers can focus on increasing emotional self-efficacy. Training and weight 
loss workshop can be designed to specifically train individuals to handle their emotional situations while trying to lose weight. In addition, tips and strategies to maintain healthy weight when obese individuals are unwell or unfit is also crucial to maintain a positive attitude toward weight loss.

Finally, individuals who are obese tend to have a negative perception toward weight loss and will be less likely to lose weight, exercise, and eat healthy. Individuals who are overweight are also less likely to have intentions to lose weight. Obese individuals' efforts to reduce body weight usually meet with very limited success. The findings support Schifter \& Icek's (1985) study that found people who have positive attitude toward losing weight and also believed that they were capable of doing so were more likely to succeed. This is a challenge faced by social marketers and public policy makers in developing countries. They need to focus on educating about the benefit and importance of losing weight, which may increase their intention to lose weight, exercise more and eating healthier.

To conclude, this study has several limitations. First, the study used samples from large cities in Indonesia which offer more access to healthier foods and sport facilities. Future studies should investigate people living in rural area with less access to healthier food. The study may investigate their food choice behaviour and physical activities. Second, despite the value of using BMI, it has some limits. The scale may overestimate body fat in individuals who have a muscular build and may underestimate body fat in individuals who have lost muscle (National Heart, Lung and Blood Institute, 2016). Third, similar to other studies, it is difficult to determine whether self-efficacy affects weight loss or whether weight loss affect self-efficacy (Bandura, 1977; Dennis \& Goldberg, 1996). Future research may facilitate an experiment to explore the effect of reciprocal interaction among behavioural, cognitivepersonal, and environmental components of individuals to determine the main cause of weight loss. 


\section{References}

Abrams, D. B., \& Niaura, R. S. (1987). Social learning theory. Psychological theories of drinking and alcoholism, 1, 131-178.

Ajzen, I. and Driver, B.E. (1991). Prediction of leisure participation from behavioral, normative, and control beliefs: an application of the theory of planned behavior. Leisure Sciences, 13, $185-204$

Ajzen, I., Fishbein, M., (1980). Understanding attitudes and predicting social behaviour. Prentice-Hall, Englewood Cliffs NJ.

Ajzen, I., \& Timko, C. (1986). Correspondence between health attitudes and behavior. Basic and Applied Social Psychology, 7(4), 259-276.

Armitage, C. and Conner, M. (1999). The theory of planned behavior: assessment of predictive validity and perceived control. British Journal of Social Psychology, 38, 35 - 5

Bandura, A. (1977). Self-efficacy: toward a unifying theory of behavioral change. Psychological review, 84(2), 191.

Bandura, A. (1982). Self-efficacy mechanism in human agency. American Psychologist, 37, 122-147.

Blue, C. L. (1995). The predictive capacity of the theory of reasoned action and the theory of planned behavior in exercise research: An integrated literature review. Research in Nursing and Health, 18, 105-121

Bradley, I., Poser, E., \& Johnson, J. (1980). Outcome expectation rating as predictors of success in weight reduction. Journal of Clinical Psychology, 36, 500-502.

Brownell, K. D., \& Cohen, L. R. (1995). Adherence to dietary regimens: 2. Components of effective interventions. Behavioral Medicine, 20, 155- 164.

Chamberlain, J. M., \& Haaga, D. A. (2001). Unconditional self-acceptance and psychological health. Journal of Rational-Emotive and Cognitive-Behavior Therapy, 19(3), 163-176.

Chamberlin, C. M., \& Zhang, N. (2009). Workaholism, Health, and Self-Acceptance. Journal of Counseling \& Development, 87(2), 159-169.

Chao, D., Farmer, D. F., Sevick, M. A., Espeland, M. A., Vitolins, M., \& Naughton, M. J. (2000). The value of session attendance in a weight-loss intervention. American Journal of Health Behavior, 24, 413- 421.

Chan, D.K.-S. and Fishbein, M. (1993) Determinants of college women's intentions to tell their partners to use condoms. Journal of Applied Social Psychology, 23, 1455-1470.

Conner, M., \& Godin, G. (2007). Temporal stability of behavioural intention as a moderator of intention-health behaviour relationships. Psychology and Health, 22(8), 875-897. 
Crowne, D. P., \& Stephens, M. W. (1961). Self-acceptance and self-evaluative behavior: A critique of methodology. Psychological Bulletin, 58(2), 104.

Carson, S. H., \& Langer, E. J. (2006). Mindfulness and self-acceptance. Journal of rationalemotive and cognitive-behavior therapy, 24(1), 29-43.

Davey, G., McClenahan, C., \& Zhao, X. (2014). Smoking intention among Chinese youth and implications for health interventions. Asia Pacific Journal of Counselling and Psychotherapy, 5(1), 71-86.

Dennis, K. E., \& Goldberg, A. P. (1996). Weight control self-efficacy types and transitions affect weight-loss outcomes in obese women. Addictive behaviors, 21(1), 103-116.

De Pelsmacker, P., L. Driesen, \& G. Rayp (2003), Are fair trade labels good business? Ethics and coffee buying intentions, Working Paper Ghent University, Faculty of Economics and Business Administration, Ghent.

Deshpande, S., Basil, M. D., \& Basil, D. Z. (2009). Factors influencing healthy eating habits among college students: An application of the health belief model. Health marketing quarterly, 26(2), 145-164.

De Vries, H., Dijkstra, M., \& Kuhlman, P. (1988). Self-efficacy: the third factor besides attitude and subjective norm as a predictor of behavioural intentions. Health education research, 3(3), 273-282.

Edell, B. H., Edington, S., Herd, B., O'Brien, R. M., \& Witkin, G. (1987). Self-efficacy and self-motivation as predictors of weight loss. Addictive Behaviors, 12(1), 63-66.

Fishbein, M., Jaccard, J. J., Davidson, A. R., Ajzen, I., \& Loken, B. (1980). Predicting and understanding family planning behaviors: Beliefs, attitudes, and intentions. Understanding attitudes and predicting social behavior, 130-147.

Fishbein, M., \& Yzer, M. C. (2003). Using theory to design effective health behavior interventions. Communication theory, 13(2), 164-183.

Flett G., Besser A., Davis R. \& Hewitt P. (2003) Dimensions of perfectionism, unconditional self acceptance and depression. Journal of Rational Emotive and Cognitive Behavior Therapy 21, 119-138

Fontaine, K. R., \& Cheskin, L. J. (1997). Self-efficacy, attendance, and weight loss in obesity treatment. Addictive Behaviors, 22(4), 567-570.

Godin, G., (1993). The theories of reasoned action and planned behavior: Overview of findings, emerging research problems and usefulness for exercise promotion. Journal of Applied Sport Psychology, 5(2): 141-157.

Godin, G., \& Kok, G. (1996). The theory of planned behavior: A review of its applications to health-related behaviors. American Journal of Health Promotion, 11, 87-98 
Grammatikopoulou, M. G., Panayiotoglou, A., \& Hassapidou, M. (2008). Evaluation of commercial weight-loss programmes in Greece. International Journal of Consumer Studies, 32(1), 59-64.

Greenspon, T. S. (2000). 'Healthy perfectionism' is an oxymoron! Reflections on the psychology of perfectionism and the sociology of science. Journal of Secondary Gifted Education, 11, 197-208.

Gupta, N., Goel, K., Shah, P., \& Misra, A. (2012). Childhood obesity in developing countries: epidemiology, determinants, and prevention. Endocrine Reviews, 33(1), 48-70.

Hagger, M., Chatzisarantis, N., \& Biddle, S. (2002). A meta-analytic review of the theories of reasoned action and planned behavior in physical activity: Predictive validity and the contribution of additional variables. Journal of Sport and Exercise Psychology, 24, 3-32.

Hausenblas, H. A., Carron, A. V., \& Mack, D. E. (1997). Application of the theories of reasoned action and planned behavior to exercise behavior: A meta-analysis. Journal of Sport and Exercise Psychology, 19, 36-51.

Hoffman, D.J. (2004). Upper limits in developing countries: warning against too much in lands of too little. Journal of the American College of Nutrition, 23(6), 610S-615S.

Hooker, D.. \& Convisser, E. (1983). Women's eating problems: An analysis of a coping mechanism. Personnel and Guidance Journal, December, 236-239.

Kemp, E., \& Grier, S. (2013). When food is more than nutrition: Understanding emotional eating and overconsumption. Journal of Consumer Behaviour, 12(3), 204-213.

Leahy-Warren, P., McCarthy, G., \& Corcoran, P. (2012). First-time mothers: social support, maternal parental self-efficacy and postnatal depression. Journal of Clinical Nursing, 21(34), 388-397.

Lee, L. L., Kuo, Y. C., Fanaw, D., Perng, S. J., \& Juang, I. F. (2012). The effect of an intervention combining self-efficacy theory and pedometers on promoting physical activity among adolescents. Journal of Clinical Nursing,21(7-8), 914-922.

Li, M., Dibley, M. J., Sibbritt, D. W., \& Yan, H. (2010). Dietary habits and overweight/obesity in adolescents in Xi' an City, China. Asia Pac J Clin Nutr, 19(1), 76-82.

MacInnes, D. L. (2006). Self-esteem and self-acceptance: an examination into their relationship and their effect on psychological health. Journal of Psychiatric and Mental Health Nursing, 13(5), 483-489.

McKinsey (2014). Obesity is one of the top three social burdens generated by human beings. Source: http://www.mckinsey.com/insights/economic_studies/how the world_could better_fight_ob esity (Accessed: 8 January 2016). 
Mcleay, F. J., \& Oglethorpe, D. (2013). Social marketing, parental purchasing decisions, and unhealthy food in developing countries: A Nigerian typology.Journal of Consumer Behaviour, 12(3), 232-242.

Meisenhelder J. (1985) Self esteem: a closer look at clinical interviews. International Journal of Nursing Studies, 22, 127-135.

Michaelidou, N., Christodoulides, G., \& Torova, K. (2012). Determinants of healthy eating: a cross-national study on motives and barriers. International Journal of Consumer Studies, 36(1), 17-22.

Montano, D. E., Kasprzyk, D. 2008. Theory of reasoned action, theory of planned behavior, and the integrated behavioral model. Health behavior and health education: Theory, Research, and practice, 4, 67-95.

Monteiro CA, Mondini L, Souza ALM, Popkin BM. (1995). The nutrition transition in Brazil. European Journal of Clinical Nutrition , 4, 105-13.

Monteiro CA, Conde WL, Popkin BM. (2004). The burden of disease from undernutrition and overnutrition in countries undergoing rapid nutrition transition: a view from Brazil. American Journal of Public Health, 94, 433-4

National Heart, Lung and Blood Institute (2016). Assessing Your Weight and Health and Risk. Source: http://www.nhlbi.nih.gov/health/educational/lose_wt/risk.htm\#limitations (Accessed: 18 January 2016).

Overseas Development Institute (2014). Overweight and obese adults reaching almost a billion in developing countries, as numbers continue to grow in richer nations. Source: http://www.odi.org/news/703-overweight-obese-adults-reaching-almost-billion-developingcountries-as-numbers-continue-grow-richer-nations (Accessed: 8 January 2015).

Previte, J., \& Gurrieri, L. (2015). Who Is the Biggest Loser? Fat News Coverage Is a Barrier to Healthy Lifestyle Promotion. Health marketing quarterly, 32(4), 330-349.

Ryff, C. D. (1995). Psychological well-being in adult life. Current directions in psychological science, 99-104.

Rubin, I. M. (1967). Increased self-acceptance: A means of reducing prejudice. Journal of Personality and Social Psychology, 5(2), 233.

Schifter, D. E., \& Ajzen, I. (1985). Intention, perceived control, and weight loss: an application of the theory of planned behavior. Journal of personality and Social Psychology, 49(3), 843.

Sejwacz, D., Ajzen, I., \& Fishbein, M. (1980). Predicting and understanding weight loss: Intentions, behaviors, and outcomes. Understanding attitudes and predicting social behavior, 101-112. 
Sheeran, P., Abraham, C., \& Orbell, S. (1999). Psychosocial correlates of heterosexual condom use: a meta-analysis. Psychological bulletin, 125(1), 90.

Shepard, L. A. (1979). Self-acceptance: The evaluative component of the self-concept construct. American Educational Research Journal, 16(2), 139-160.

Sheppard, B. H., Hartwick, J., \& Warshaw, P. R. (1988). The theory of reasoned action: A meta-analysis of past research with recommendations for modifications and future research. Journal of Consumer Research, 15, 325-343.

Sobal J. \& Stunkard AJ (1989). Socioeconomic status and obesity: a review of the literature. Psychological Bulletin 105, 260-275.

Strachan, S. M., Woodgate, J., Brawley, L. R., \& Tse, A. (2005). The relationship of selfefficacy and self-identity to long-term maintenance of vigorous physical activity. Journal of Applied Biobehavioral Research, 10, 98 -112. doi:10.1111/j.1751-9861.2005.tb00006.x

Stunkard AJ. (2000) Factors in obesity: current views. In: Peña M, Bacallao J, editors. Obesity and poverty: a new public health challenge. Washington, DC: Pan American Health Organization, 23-8.

Sweet, S. N., Fortier, M. S., Strachan, S. M., \& Blanchard, C. M. (2012). Testing and integrating self-determination theory and self-efficacy theory in a physical activity context. Canadian Psychology/Psychologie canadienne, 53(4), 319.

Tanner, C. and S. W. Kast (2003), "Promoting Sustainable Consumption: Determinants of Green Purchases by Swiss Consumers. Psychology and Marketing, 20(10), 883-902

Theodorakis, Y. (1994). Planned behavior, attitude strength, role identity, and the prediction of exercise behavior. The Sport Psychologist, 8, $149-165$.

Trafimow, D. (2000). Habit as both a direct cause of intention to use a condom and as a moderator of the attitude-intention and subjective norm-intention relations. Psychology and Health, 15(3), 383-393.

Usfar, A. A., Lebenthal, E., Achadi, E., \& Hadi, H. (2010). Obesity as a poverty-related emerging nutrition problems: the case of Indonesia. Obesity reviews, 11(12), 924-928.

Vermeir, I., \& Verbeke, W. (2006). Sustainable food consumption: Exploring the consumer "attitude-behavioral intention" gap. Journal of Agricultural and Environmental Ethics, 19(2), 169-194.

Wang, Y., \& Lim, H. (2012). The global childhood obesity epidemic and the association between socio-economic status and childhood obesity. International Review of Psychiatry, 24(3), 176-188.

World Health Organization. (1998). Obesity: preventing and managing the global epidemic. Working Group on Obesity. Geneva, World Health Organization. 
World Health Organization (2009). Population-based prevention strategies for childhood obesity: report of a WHO forum and technical meeting. Geneva: World Health Organization. 


\section{Appendix}

Figure 1. Conceptual Framework




Table 1. Demographic Profile of Respondents.

\begin{tabular}{|c|c|c|}
\hline & Frequency & Percentage \\
\hline \multicolumn{3}{|l|}{ Gender } \\
\hline Male & 143 & $29 \%$ \\
\hline Female & 227 & $67 \%$ \\
\hline Undeclared & 19 & $4 \%$ \\
\hline \multicolumn{3}{|l|}{ Age } \\
\hline $18-24$ years & 248 & $50 \%$ \\
\hline $25-34$ years & 142 & $28 \%$ \\
\hline $35-44$ years & 70 & $14 \%$ \\
\hline 45 years $<$ & 39 & $8 \%$ \\
\hline \multicolumn{3}{|l|}{ Income } \\
\hline$<$ Rp. 20 million & 257 & $52 \%$ \\
\hline Rp. 21-40 million & 94 & $19 \%$ \\
\hline Rp. 41-80 million & 59 & $12 \%$ \\
\hline Rp. 81 million & 33 & $7 \%$ \\
\hline Undeclared & 56 & $11 \%$ \\
\hline \multicolumn{3}{|c|}{ Education } \\
\hline High School or lower & 204 & $40.9 \%$ \\
\hline Diploma & 74 & $14.8 \%$ \\
\hline Undergraduate & 146 & $29.3 \%$ \\
\hline Post Graduate & 55 & $11.0 \%$ \\
\hline Others & 4 & $0.8 \%$ \\
\hline Undeclared & 16 & $3.2 \%$ \\
\hline \multicolumn{3}{|l|}{$\overline{\text { BMI }}$} \\
\hline Normal Weight & 278 & $55 \%$ \\
\hline Overweight & 133 & $27 \%$ \\
\hline Obese & 88 & $18 \%$ \\
\hline
\end{tabular}

36

37

38

39

40

41

42

43

44

45

46

47

48

49

50

51

52

53

54

55

56 
Table 2. Confirmatory Factor Analysis

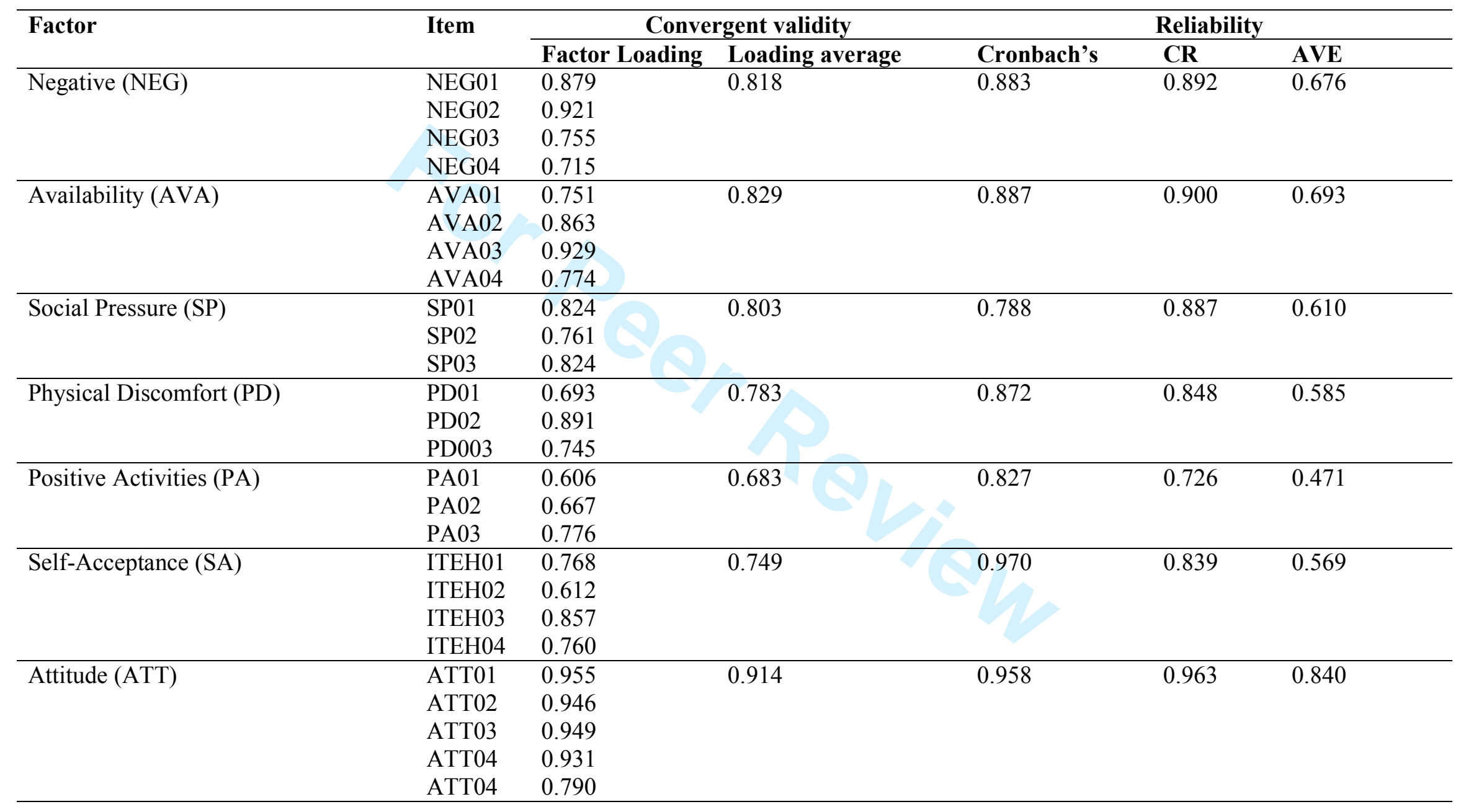


Table 2. Confirmatory Factor Analysis (Cont)

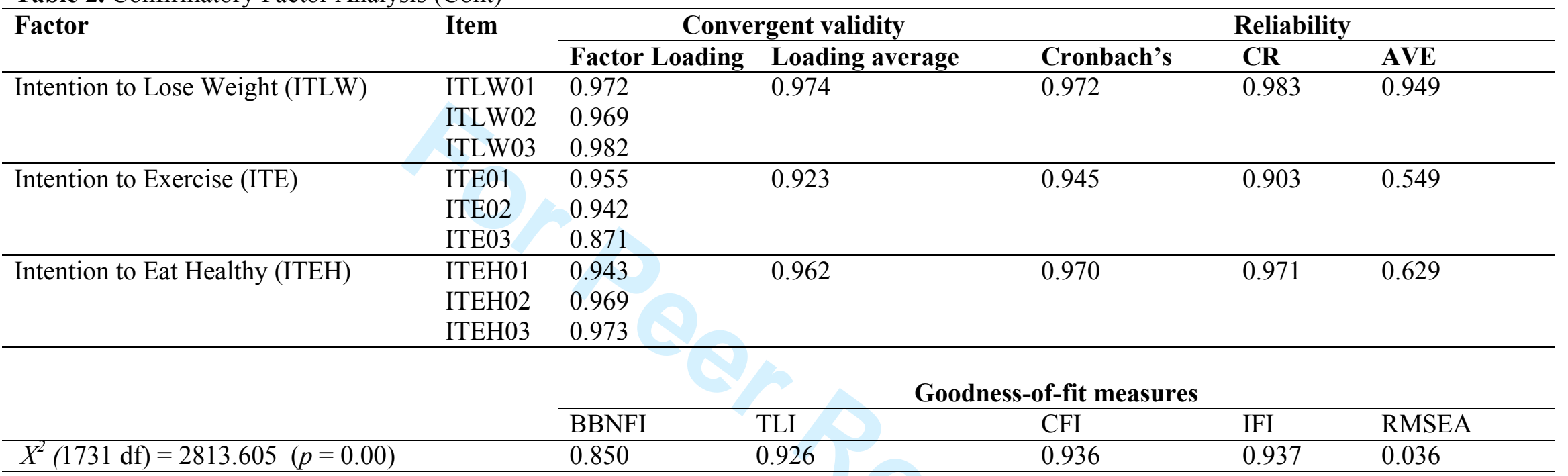

Notes: Measure instrument psychometric properties

CR Composite Reliability, AVE Average Variance Extracted 
Table 3. Discriminant Validity - All Constructs

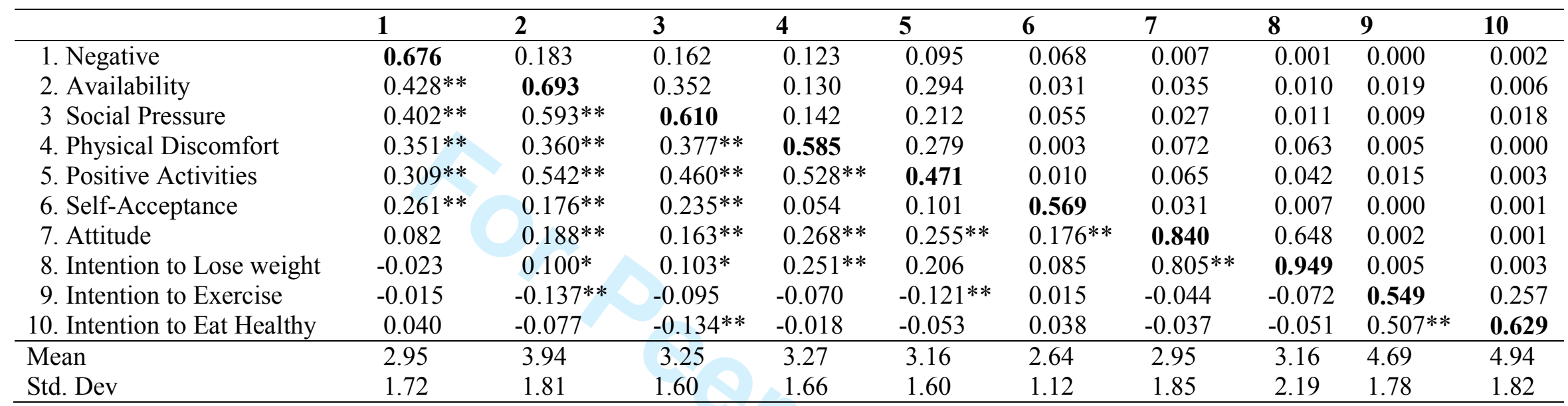

Notes: Values below the diagonal are bivariate correlations between the constructs, bold diagonal elements represents the Average Variance Extracted (AVEs) for the relevant construct; Values above the diagonal represent squared correlations; Values below the diagonal represent correlations 
Table 4. Structural Equation Model Results

\begin{tabular}{|c|c|c|c|c|}
\hline \multirow[t]{2}{*}{ Hypotheses } & \multirow[t]{2}{*}{ Structural relationship } & \multicolumn{3}{|c|}{ Standardised coefficient } \\
\hline & & Normal & Overweight & Obese \\
\hline H1a & Self-Acceptance $\rightarrow$ Negative & $0.277 * *$ & $0.215 *$ & $0.523 * *$ \\
\hline $\mathrm{H} 1 \mathrm{~b}$ & Self-Acceptance $\rightarrow$ Available & $0.149 *$ & $0.214 *$ & $0.400 * *$ \\
\hline $\mathrm{H} 1 \mathrm{c}$ & Self-Acceptance $\rightarrow$ Social & $0.310 * *$ & 0.167 & $0.421 * *$ \\
\hline H1d & Self-Acceptance $\rightarrow$ Physical & 0.002 & 0.049 & 0.218 \\
\hline H1e & Self-Acceptance $\rightarrow$ Positive & 0.131 & 0.098 & $0.407 * *$ \\
\hline $\mathrm{H} 2$ & Self-Acceptance $\rightarrow$ Attitude & $0.148 *$ & 0.134 & $0.363 *$ \\
\hline $\mathrm{H} 3 \mathrm{a}$ & Negative $\rightarrow$ Attitude & -0.057 & -0.233 & $-0.566 * *$ \\
\hline $\mathrm{H} 3 \mathrm{~b}$ & Available $\rightarrow$ Attitude & 0.014 & 0.092 & 0.238 \\
\hline $\mathrm{H} 3 \mathrm{c}$ & Social $\rightarrow$ Attitude & -0.168 & -0.038 & 0.237 \\
\hline $\mathrm{H} 3 \mathrm{~d}$ & Physical $\rightarrow$ Attitude & 0.123 & 0.377 & $0.313 *$ \\
\hline $\mathrm{H} 3 \mathrm{e}$ & Positive $\rightarrow$ Attitude & $0.278 *$ & 0.046 & -0.127 \\
\hline $\mathrm{H} 4 \mathrm{a}$ & Attitude $\rightarrow$ Intention to Lose Weight & $0.845 * *$ & $0.866 * *$ & $0.783 * *$ \\
\hline $\mathrm{H} 4 \mathrm{~b}$ & Attitude $\rightarrow$ Intention to Exercise & -0.035 & 0.085 & $0.218 *$ \\
\hline $\mathrm{H} 4 \mathrm{c}$ & Attitude $\rightarrow$ Intention to Eat Healthy & -0.044 & 0.133 & $0.238 *$ \\
\hline
\end{tabular}




\section{--- END OF MANUSCRIPT --

